
Volume 17 Number 1, April 2019 pp $112-.122$

\title{
EFFECT OF MATERNAL HEALTH PROGRAMME ON RURAL WOMEN AGRICULTURAL ACTIVITIES IN OWERRI AGRICULTURAL ZONE OF IMO STATE, NIGERIA
}

\author{
Helen A. Egwuonwu \\ Dept. of Agricultural Economics, Extension and Rural Development. \\ P.M.B 2000 Imo State University, Owerri \\ E-mail: egwuonwu.helen@yahoo.com
}

\begin{abstract}
The study analyzed the effects of maternal health programme on rural women agricultural activities in Owerri agricultural zone of Imo state, Nigeria. Specifically, the study described the socio-economic characteristic of rural women; identified the various agricultural activities rural women are involved-in; ascertained the perceived effect of maternal health programme on agricultural activities and identified the barriers of women in participating in maternal health programme in the area. Multistage sampling procedure was used in the selection of 120 women. Data was collected with structured questionnaire and analyzed with descriptive and inferential statistical tools. Mean age was 37 years. Majority (92.50\%) of the women were married with an average household size of 5 persons. Also, majority (75\%) had primary education while a greater proportion (92.50\%) were members of social organizations. Average farming experience and farm income were 17 years and $\$ 47,853$ respectively. Majority (82.50\%) had access to maternal and health care services. Planting (96.67\%), transplanting (83.33\%) and weeding (79.17\%) were identified as the major agricultural activities they were involved-in. Result also showed that there were positive and significant effects of maternal health care programme on women agricultural activities in the area. There were significant increase in farm produce (mean $=3.90)$ and women involvement in agricultural activities (mean = 3.63) among other positive effects in the area. Estimated regression result showed that the socio-economic characteristic of the women influence their perceived effectiveness of maternal health programme in the area. The F-ratio was (6.591), indicating the overall significant of the regressor at $1 \%$ level of probability. The maternal health care programme has been invaluable to women in the area as well as enhancing their engagement in agricultural and entrepreneurship activities in the area. However, exorbitant charges (99.17\%) and long distance between house and health care centre (95.83\%) were barriers to participating in maternal health programmes. It was therefore recommended that high fees should be reduced and health centres be established closer to the women community as these would increase their access to maternal health programme and engagement in agricultural entrepreneurship activities in the area.
\end{abstract}

Keywords: Maternal Health Programme, Rural women, Agricultural activities. https://dx.doi.org/10.4314/jafs.v17i1.9 


\section{INTRODUCTION}

The role that women play and their position in meeting the challenges of agricultural production and rural development are quite dominant and prominent in Nigeria (Nuhu et al., 2014; Egwuonwu, 2017). Their relevance and significance therefore cannot be overemphasized. The rural women play a key role in supporting their households and communities in achieving food and nutrition security, generating income and improving rural livelihoods and overall well being (Nnadi et al., 2012). The emphasis on rural areas is based on the studies that over 70 percent of the Nigerians population live in the rural areas of which women are in the majority. With little or no proper health care services and facilities, even where they exist, striking rural poverty hinders most of them assessing these services (Singh et al., 2014). Health plays an important role in agricultural production since rural women mostly engage in agriculture. Poor health limits the capabilities of the labour force to work leading to decrease in rural productivity and this has significant effect on the growth of the nation (Egwuonwu, et al., 2017). One of the millennium Development Goals (MDGS) is to improve the maternal health, this is in recognition of the importance of rural women's health (UNDP, 2004).

The term Maternal Health is described as the health of women during pregnancy, childbirth and the postpartum period (World Health Organization (WHO), 2011). It encompasses the health care dimensions of family planning, preconception, prenatal, and postnatal care in order to ensure a positive and fulfilling experience in most cases and reduce maternal morbidity and mortality in other cases (Okoli et al., 2016). While motherhood is often a positive and fulfilling experience, for too many women it is associated with suffering, ill-health and even death. The major direct causes of maternal morbidity and mortality include hemorrhage, infection, high blood pressure, unsafe abortion, and obstructed labour (Shujaat et al., 2014). Complications of pregnancy and childbirth are a leading cause of maternal morbidities and mortalities for women of reproductive age (15 - 49 years) in developing countries (Hauwa, 2011). The United Nations Population Fund (UNFPA) estimated that about 289,000 women died of pregnancy or childbirth related causes in 2013 and these causes range from severe bleeding to obstructed labour, all of which have highly effective interventions (Emelumadu et al., 2014).

Maternal health also has developmental consequences beyond its more obvious health ones. This was recognized by world leaders at the Sustainable Summit, in 2015, by including it as the fifth Sustainable Development Goal (SDG). SDG 5 focuses on improving maternal health by 2030 (SDG, 2016). Sustainable Development Goal 5 sets a target of reducing the global maternal mortality ratio to less than 70 per 100,000 live births by 2030. So far, progress in developing countries, including Nigeria in reducing maternal mortality and providing family planning services have been slow in achieving this (WHO, 2011). It has been observed that Nigeria is off track in meeting SDG 5 and according to the United Nations mortality estimates, Nigeria has only achieved an average of $1.1 \%$ annual reduction in under-five mortality since 2015 (United Nation, 2015). Similarly, in order to meet SDG 5, Nigeria needed to have achieved an annual Journal of the Faculty of Agriculture and Veterinary Medicine, Imo State University Owerri website: www ajol.info 
reduction rate of $40 \%$ in the 13 years leading to 2030 (WHO, 2011). However, particularly in Imo State, Nigeria, various maternal health programmes are relatively not known as well as its effectiveness to beneficiaries. It is on this background that the study was undertaken.

The broad objective of the study was to assess the effects of maternal health programme on rural women agricultural activities in Owerri agricultural zone of Imo State, Nigeria. The specific objectives of the study were to:

i. describe the socio-economic characteristic of rural women in the study area;

ii. identify the various agricultural activities rural women are involved-in the study area;

iii. ascertain the perceived effect of maternal health programme on agricultural activities

iv. identify the barriers of women in participating in maternal health programme.

\subsection{Hypothesis of the Study}

The null hypothesis tested was that the socio-economic characteristics of women do not influence their perceptions on the effectiveness of maternal health programme in the study area.

\section{METHODOLOGY}

The study was carried out in Owerri agricultural zone of Imo State, Nigeria. The population of the study was rural women in Owerri agricultural zone in Imo State, Nigeria. This study adopted multi stage sampling procedure. In the zone, two Local Government Areas (LGAs) were randomly selected. In each of the LGAs selected, three (3) rural communities were randomly selected. From the six (6) communities selected, twenty (20) rural women were then randomly selected from each of the communities giving a sample size of one hundred and twenty (120) women. The list of the women which formed the sample frame was collected from the women leaders in the communities. Data for the study were generated from primary source through the use of a set of structured questionnaires. Data collected were analyzed using descriptive (frequency, mean and percentage) and inferential statistics (logistic regression). Likert type scale was used in measuring the perceived effect of maternal health programme on women. The mean scores were obtained by adding up the weighted values and dividing by the number of scales. The values of the Likert scale rating were added together and then divided by the number of scales to obtain the discriminating index of 2.5 (e.g $4+3+2+1=10 / 4=2.5$ ). Multiple regression was used in testing the hypothesis.

\section{RESULTS AND DISCUSSION}

\section{Socio-economic characteristics of the rural women}

The result in Table 1 revealed the mean age of the respondents was 37 years. Majority (75.00\%) of the women had primary education, women married were $(92.50 \%)$ while the mean experience in farming activities was 17.00 years. The mean household size was 5 persons, majority $(92.50 \%)$ of the women in the area belonged to one form of social organization or the other, the mean monthly farm income was $\$ 27,853.00$ shows that greater proportion $(82.50 \%)$ of the women in the study area had access to health services. 


\section{Agricultural activities women are involved-in}

The result of the women distribution based on agricultural activities women were involved in is presented in Table 2. It revealed that majority (96.67\%) of the women were involved in planting of different crops in the study area. Women were involved in transplanting (83.33\%), weeding $(79.17 \%)$ and fertilizer application $(75.83 \%)$. Similarly, the women were involved in herbicide application (72.50\%), pesticides application (70.83\%) and harvesting (68.33\%). Also, processing $(66.67 \%)$, packaging $(60.83 \%)$, storage $(58.33 \%)$, land preparation $(54.17 \%)$ and marketing of agricultural produce $(50.83 \%)$ were identified by the women as the agricultural activities they area involved-in. The finding implies that the women were involved in various forms of agricultural activities in the area. The study is in line with the finding of Gashaw and Alemayehu (2015) who opined that women were involved in more than one form of agricultural activities to increase their income and standard of living.

\section{Perceived health effect of maternal programme on agricultural activities}

The result of the distribution of women based on perceived effect of maternal health programme on agricultural activities as shown in Table 3. The women reported that maternal health programme has been of benefit to them as they strongly agreed that there is increase in crop production $(84.17 \%)$, increase in farm produce $(89.17 \%)$, increase in women involvement in agricultural activities $(81.67 \%)$, increase in marketing of agricultural produce $(90.00 \%)$, increased efficiency in processing and storage of agricultural produce (85.33\%). The findings implies that maternal health programme have been beneficial to women and agricultural activities in the area. Similarly, despite strong agreement to mist of the statements, there was disagreement in increased access to farm land (63.83\%), increased access to farm inputs $(45.00 \%)$ and increased access to extension agents $(64.17 \%)$. The study of Ogunlela and Mukhtar (2009) opined that women contribute tremendously to agricultural production. It is gratifying, therefore, that maternal health programme have become beneficial to the women in increasing their agricultural production and access to health care services.

\section{Women barrier in participating in maternal health programme}

The result of the distribution based on women barrier in participating in maternal health programme is presented in Table 4 . The result indicates that the women complained of exorbitant charges $(99.17 \%)$, long distance to health care centre $(95.83 \%)$ and inadequate information $(83.33 \%)$. The findings are in line with the study of Nuhu et al., (2014) who observed that women in Nigeria are challenged by high fees, limited information and long distance of health centres in participating fully in maternal health programme. Similarly, the women identified health care centres not always open (80.83\%), poor access to health care facilities (76.67\%), poor trained health officers $(75.00 \%)$, and poor access to health care personnel's $(70.83 \%)$ as their barrier in participating in maternal health programme in the area.

Also, illiteracy (67.50\%), unfriendly health officers (64.17\%) and lack of mobility (62.50\%) were reported by the women as their barrier to participating in maternal health programmes. 
Illiteracy makes most of the women to understand the important of maternal health programme to their lives. There is no doubt that these barriers are responsible for high maternal mortality and morbidity faced by women and also the major reason while the woman could not take full advantage of maternal health programme in the area. Curbing these barriers will not just be vital in reducing maternal mortality and morbidity but enhancing women participation in agricultural and entrepreneur activities in the area and maybe more.

\section{Influence of women socio-economic characteristic on their perceived effects of maternal health programme}

The result of the influence of women socio-economic characteristics on their perceived effects of maternal health programme in the area is presented in Table 5. Four functional forms (linear, semi log, double log, and exponential forms) were tried. Based on the statistical significance of the coefficients, the double-log regression function was chosen as the lead equation. The result revealed that coefficients of educational level, marital status, membership of organizational association, access to mobility, household size, income and access to health care services were significant and related to perceived effects of maternal health programme.

The coefficient of educational level was positive and significant at $1 \%$ level of probability implying that high educational level leads to a significant increase in the effectiveness of maternal health programmes and as well as enhance women participation in agricultural activities in the area. This is line with the findings of Olatunji (2013) who opined that exposure to higher level of education will contribute positively and significantly in the understanding of the importance of maternal health programmes among women. Also, the coefficient of marital status was positive and significant at $1 \%$ level of probability, this implies that maternal health programmes in the area is basically for married women, who are seen to be capable of giving birth, nursing the baby, caring for their young kids, responsible according to family and societal standards. The studies of Emelumadu et al., (2014) opined that married women tends to have easy significant access to land and large family size which they traditionally owned to increase their participation in any form of agricultural activities.

The coefficient of membership of organization was positive and significant at 5\% level of probability. The finding implies that those who are members of social organization participated more in maternal health programme than their counterpart who are not member of any social organization. The studies of Babalola and Fatusi (2009) reported that membership of social organization affords members vast opportunities which includes; sharing of relevant, modern and trending information, projecting a collective demand and networking together about modern women contemporary issues within their domain. The coefficient of access to mobility was also positive and significant at $1 \%$ level of probability implying that those who have access to mobility are expected to participate more in maternal health programme than their counterpart who do not have. The study of Singh et al., (2014) reported that proximity of health care centre to community afford women significant access to health care services and reduces child mortality and mobility. 
The coefficient of household size was positive and significant at $1 \%$ level of probability implying large household size is expected to compliment labour at home and farms hence given women positive access to participate actively in maternal health programme in the area. The findings tallies with the study of Fotso et al., (2009) who reported that large household size ensures availability of farm labour and increase women/nursing or expectant mothers access to participate actively in maternal health programme in the area. The coefficient of income was positive and significant at $1 \%$ level of probability implying maternal health programme can promote women participation in agricultural activities in the area. The result implies that the women in the area have a moderate monthly farm income which could increase their participation in maternal health programmes in the area. The coefficient of access to health care services was positive and significant at $1 \%$ level of probability. The finding implies that those who have access to health care services participated more in maternal health care programme in the area than their counterpart who lack access. The result shares view with the studies of Okoli et al., (2016) who asserted that access to health care services reduces child mortality and morbidity as well as raising women standard of living.

The F-ratio (6.591) which determines the overall significance of the regression model is highly significant at $1 \%$ level of probability implying that the regression model has very high explanatory power; hence the study concludes that women socio-economics characteristics women had a significant influence on their perceived effectiveness of maternal health programme in their agricultural activities in area.

\section{CONCLUSION}

Maternal health programme plays an important role in agricultural development and improving the quality of life of women since many women make up the agricultural labour force. In conclusion, almost all the women were aware of various maternal health care programme in the area. Result showed a high level of participation in Antenatal care (ANC), Postnatal care (PNC), maternal and child nutrition and family planning amongst others, while Skilled Birth Attendance training had low level of participation. There was significant increase in farm produce and more women were involved in agricultural activities. The maternal health care programme has been invaluable to the women as well as enhancing their engagement in agricultural and entrepreneurship activities in the study area. For women to be involved in agricultural activities, the study recommends that, the government at all levels and Non-Government Organization should intensify effort on dissemination of information on the importance of maternal health care programme in the study area. Also, high service charge for maternal health programme should be reduced to give women more access to health care services. The women should be encouraged to join social organization so as to enhance their access to agricultural activities as well and maternal health programme in the area.

\section{REFERENCES}


Babalola, S. and Fatusi, A. (2009). 'Determinants of Use of Maternal Health Services in Nigeria - Looking Beyond Individual and Household Factors'. BMC Pregnancy and Childbirth 2009, [Online] Available from: http://www.biomedcentral.com/content/pdf/1471-2393-9-43.pdf.

Emelumadu, O.F., Ukegbu, A. U., Ezeama, N. N., Kanu, O. O., Ifeadike, C. O. and Onyeonoro, U. U (2014). Socio-demographic Determinants of Maternal Health-Care Service Utilization among Rural Women in Anambra State, South East Nigeria. Ann Med Health Sci Res;4:374-82

Egwuonwu, H.A., Matthews-Njoku, E.C., Nnadi, F.N. and Ukpongson, M.A. (2017). Assessment of the Effects of Maternal Health Care Services in Combating Hidden Hunger among Rural Women in Imo State, Nigeria. Proceeding of the International Conference on Food Security and Hidden Hunger held in Federal University

Ndufu Alike Ikwo (FUNAI), Ebonyi State, Nigeria, October 8 to 11, 2017.

Egwuonwu, H.A. (2017). Analysis of the Perceived Effects of Selected Development Interventions on Rural Women in Imo State, Nigeria. Research Journal of Sociology Vol. 5 No. 8

Fotso, J., Ezeh, A.C. and Essendi, H. (2009).'Maternal Health in Resource-Poor Urban Settings: How Does Women's Autonomy Influence the Utilization of Obstetric Care Services?' Reproductive Health 2009, 6:9

Gashaw, A and Alemayehu F (2015). Assessment of Rural Women's Participation In Agricultural Production: The Case of Awaro Kora Peasant Associations, Ambo District West Shewa Zone, Oromia Region; International Journal of Political Science and Development; Vol. 3(1), pp. 40-49

Hauwa, S.A (2011). Utilization of Maternal Health Care Services in Nigeria: An Analysis of Regional Differences in the Patterns and Determinants of Maternal Health Care Use; Dissertation Submitted in Partial Fulfilment of the Requirement for the Degree of Master of Public Health, the University of Liverpool

Nnadi, F.N., Chikaire. J., Osuagwu, C.O., Ihenacho, R.A and Egwuonwu, H.A (2012). Mobilizing Women for Food Security, Poverty Reduction and Rural Development in Nigeria: The Role of Land and Tenure Rights. Greener Journal of Agricultural sciences vol. 2(3), pp 90-101.

Nuhu, N.S., Donye, A.O and Bawa, D.B (2014). Barriers to Women Participation in Agricultural Development in Bauchi Local Government Area of Bauchi State, Nigeria; Agriculture and Biology Journal of North America; 5(4).166-174 
Ogunlela, Y. I. and Mukhtar, A. A. (2009). Gender Issues in Agriculture and Rural Development in Nigeria: The Role of Women. Humanity and Social Sciences Journal 4 (1): 1930

Okoli, U., Mohammed S.A and Ejeckam, C. (2016). Strengthening Primary Health Care Services in Rural Nigeria: The Potential of Using Midwives as Skilled Birth Attendants. Health System Policy Res. 2016, 3:2.

Olatunji, B (2013). Assessment of Maternal Health Intervention Programme of Delta State, Nigeria: Application of the U.N Process Indicators; Public Policy and Administration Research; Vol.3, No.9,Pp: 62-71

Shujaat, F., Durr-E-Nayab, and G. M. Arif (2014). Welfare Impact of the Lady Health Workers Programme in Pakistan; The Pakistan Development Review 53:1; pp. 49-73

Singh, A., Kumar, A, and Pranjali, P. (2014). Utilization Of Maternal Healthcare among Adolescent Mothers in Urban India: Evidence from DLHS-3. PeerJ.2014;2, e592.

Sustainable Development Goals (SDG) (2016)."Future We Want - Outcome document .: . Sustainable Development Knowledge Platform". $\quad$ Sustainable development.un.org. Retrieved 11 October 2016.

UNDP (2004). National Millennium Development Goals Report 2004

United Nations (2015). Sustainable Development Goals, The Road to Dignity, UN Secretary General's Office.

World Health Organization (WHO) (2011). 'Maternal Mortality Ratio'. Health Statistics and Health Information System. 
$\begin{array}{lll}\text { Volume } 17 \text { Number 1, April } 2019 \text { pp } & 112-.122\end{array}$

Table 1: Socio-economic Characteristics of the Rural Women

\begin{tabular}{llll}
\hline Socio-economic characteristics & Frequency/mode & Percentage & Mean \\
\hline Age (Years) & $26-35$ & 50.83 & 37years \\
Level of education & Primary education & 75.00 & \\
Marital Status & Married & 92.50 & \\
Farming experience (Years) & $10-19$ & 86.67 & $\mathbf{1 7}$ years \\
Household size & $6-10$ & 71.67 & $\mathbf{5}$ person \\
Membership of social organization & Member & 92.50 & \\
Income (Naira) & $21,000-30,000$ & 69.17 & $\mathbf{N 2 7 , 8 5 3 . 0 0}$ \\
Access to health service & Access & 82.50 & \\
\hline
\end{tabular}

Table 2: Distribution of the Women by Agricultural Activities they are involved-in

\begin{tabular}{lll}
\hline Agricultural Activities & Frequency & Percentage (\%) \\
\hline Planting & 116 & 96.67 \\
Transplanting & 100 & 83.33 \\
Weeding & 95 & 79.17 \\
Fertilizer application & 91 & 75.83 \\
Herbicide application & 87 & 72.50 \\
Pesticide application & 85 & 70.83 \\
Harvesting & 82 & 68.33 \\
Processing & 80 & 66.67 \\
Packaging & 73 & 60.83 \\
Storage & 70 & 58.33 \\
Land preparation & 65 & 54.17 \\
Marketing of agricultural produce & 61 & 50.83 \\
\hline
\end{tabular}

*Multiple responses were recorded. 
Table 3: Distribution of the Perceived Effect of Maternal Health Programme on Agricultural Activities

\begin{tabular}{llllll}
\hline Effects & $\begin{array}{l}\text { Strongly } \\
\text { Agree (4) }\end{array}$ & $\begin{array}{l}\text { Agree } \\
\mathbf{( 3 )}\end{array}$ & $\begin{array}{l}\text { Disagree } \\
\mathbf{( 2 )}\end{array}$ & $\begin{array}{l}\text { Strongly } \\
\text { Disagree(1) }\end{array}$ & Mean \\
\hline $\begin{array}{l}\text { There is increase in crop } \\
\text { production }\end{array}$ & 84.17 & 7.50 & 5.00 & 3.33 & $3.72^{*}$ \\
$\begin{array}{l}\text { There is increase in farm produce } \\
\text { There is increase in women }\end{array}$ & 89.17 & 5.83 & 3.33 & 1.67 & $3.90^{*}$ \\
$\begin{array}{l}\text { involvement in agricultural } \\
\text { activities }\end{array}$ & 81.67 & 9.17 & 5.83 & 3.33 & $3.63^{*}$ \\
$\begin{array}{l}\text { There is increased access to farm } \\
\text { land }\end{array}$ & 9.17 & 20.00 & 65.83 & 5.00 & 2.03 \\
$\begin{array}{l}\text { There is increased access to farm } \\
\text { inputs }\end{array}$ & 26.67 & 10.00 & 45.00 & 18.33 & 2.41 \\
$\begin{array}{l}\text { There is increase in marketing of } \\
\text { agricultural produce }\end{array}$ & 90.00 & 5.00 & 3.33 & 1.67 & $3.95^{*}$ \\
$\begin{array}{l}\text { Increased efficiency in processing } \\
\text { and storage of agricultural produce }\end{array}$ & 85.83 & 5.00 & 2.50 & 4.17 & $3.80^{*}$ \\
$\begin{array}{l}\text { There is increase in livestock } \\
\text { production }\end{array}$ & 7.50 & 4.17 & 5.00 & 3.33 & $3.88^{*}$ \\
$\begin{array}{l}\text { There is increased access to } \\
\text { extension agents }\end{array}$ & 18.33 & 8.33 & 64.17 & 9.17 & 2.30 \\
\hline
\end{tabular}

*Mean greater than 2.50 Accepted

Table 4: Distribution of Women Barrier in Participating in Maternal Health Programme

\begin{tabular}{lll}
\hline Barriers & Frequency & Percentage (\%) \\
\hline Exorbitant charges & 119 & 99.17 \\
Long distance between house and health care centre & 115 & 95.83 \\
Inadequate information & 100 & 83.33 \\
Health care centres not always open & 97 & 80.83 \\
Poor access to health care facilities & 92 & 76.67 \\
Poor trained health officers & 90 & 75.00 \\
Poor access to health care personnel's & 85 & 70.83 \\
Illiteracy of women & 81 & 67.50 \\
Unfriendly health officers & 77 & 64.17 \\
Lack of mobility & 75 & 62.50 \\
\hline
\end{tabular}

Multiple responses were recorded

Journal of the Faculty of Agriculture and Veterinary Medicine, Imo State University Owerri website: www ajol.info 
Table 5: Estimated Influence of Women Socio-economic Characteristic on their Perceived Effectiveness of Maternal Health Programme on their Agricultural Activities

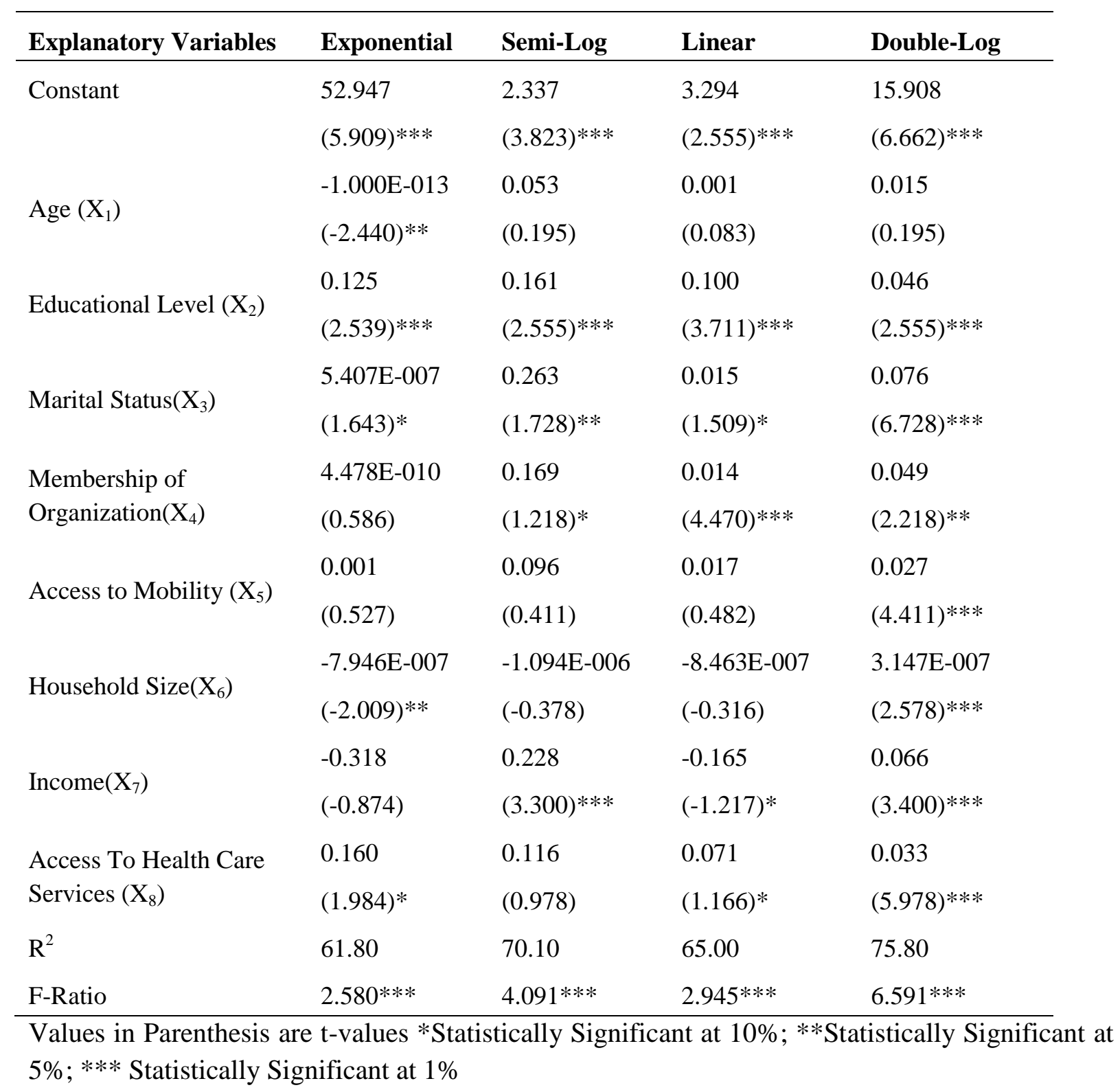

